\title{
Dupla Liderança em Organizações Complexas
}

\author{
Amitai Etzioni
}

da Columbia University

Trad. de Caetana Myriam Parente Cavalcante

O presente trabalho tenta a integração teórica entre o modêlo Bales-Parsons para pequenos grupos e uma teoria de organizações complexas. As posições organizacionais dos lideres expressivos e instrumentais são vistas como variáveis críticas, que afetam, tanto o preenchimento das necessidades funcionais dos grupos envolvidos, como o engajamento do grupo nas metas da organização. As organizações complexas se distinguem segundo a natureza de stras metas, poder empregado e o nivel de engajamento que requerem dos niveis inferiores. As relações entre o pequeno grupo e a organização complexa são revistas para cada tipo. Estals consideriações teóricas são aplicadas ao estudo e administração de prisões, a orientação de "relações humanas" na in-

A dustria, hospitais de doenças mentais e escolas.

sistemas sociais, organizações complexas, como a teoria de outros idéias e periodos de lidações, a qualidade dassolidação. Em uma das primeiras consocombinando-se a tradicão teoria foi consideràvelmente melhorada, descobertas dos estudos de formal de estrutura com as idéias e orientação de Kurt Lewin pequeno grupo realizados segundo a zado pelos conceitos de Elton Mayo. O resultado é simboliformal e informal). grupos existentes dentros, a articulação de organizações com os para que seja esgotado ou fora delas é assunto por demais vasto, 
ser agora a ocasião para um outro esfôrço no sentido de integrar a análise de pequenos grupos com aquela de organizações complexas.

Uma orientação particularmente promissora parece ser a da união entre a análise estrutural-funcional de pequenos grupos de Bales-Parsons e as linhas mestras da análise de organizaçöes complexas. Os estudos de pequenos grupos até aqui têm obtido grande parte dos seus dados de grupos criados artificialmente em laboratórios de ciências sociais, e de grupos "naturais" em ambientes "naturais", principalmente familias em comunidades tribais. Comparativamente, poucos dados têm sido obtidos, e poucas proposições formuladas, para a análise estrutural-funcional de pequenos grupos "naturais" dentro de organizações complexas, isto é, em ambientes artificiais. Uma articulação teórica dêste tipo é u objetivo do presente artigo. Para realizá-la, procurarei um outru avanço recente: o estudo comparativo de organizações. Tentarei então mostrar que, se a teoria assim entendida é válida, surgirão implicações para as esferas principais da Sociologia aplicađa, acentuando mais uma vez que o esfôrço para teorização é apenas uma etapa vencida do bem fundado trabalho aplicado.

De um ponto-de-vista teórico, a articulação entre pequenos grupos funcionando dentro de organizações complexas e seu ambiente organizacional é dupla: em primeiro lugar, a organização afeta o preenchimento das necessidades funcionais dêsses grupos e, em segundo lugar, a forma por que essas funções são desempenhadas afeta, por sua vez, o funcionamento da própria organização. E essencial que se mantenha bem distintos os dois sistemas de referência: dizer que o mesmo ato, papel ou lider têm atribuições tanto organizacionais como de grupo, não significa, de modo algum, que as funções sejam idênticas.

\section{DUPLA LIDERANÇA EM AMBIENTES NÃO ORGANIZACIONAIS}

Fazendo uso do direito de interpretar, apresentarei a seguir um breve resumo da análise de pequenos grupos de Bales-Parsons, a qual se baseia largamente em estudos experimentais. Para meus objetivos presentes, é fora de dúvida que a idéia mais importante é a de que se os pequenos grupos orientados para o trabalho devem operar com eficiência, dois tipos de liderança devem existir, e ambos devem apoiar-se mùtuamente. Esses grupos tendem a desenvolver dois tipos de lider: um que é chamado "expressivo" (pessoal ou sócio-emocional), que se coloca acima dos outros membros em aspectos como "demonstrando solidariedade" e "pedindo sugestões"; o outro é o tipo de lider chamado "instrumental" 
(ou orientado para o trabalho), que se destaca dos demais membros do grupo em atitudes de "dar sugestões" e "mostrar desacôrdo".

A distinção entre orientação expressiva e instrumental não se limita a unıa classificação de liderança. Todos os atos podem ser classificados como "expressivos" ou "instrumentais". Os papéis podem ser classificados de acôrdo com a prevalência do tipo de comportamento. Além disso, a mesma distinção analítica pode ser aplicada às necessidades funcionais de sistemas sociars. Neste caso, o instrumental se refere à necessidade de adquirir recursos ou meios, e à sua distribuição entre os vários grupos do sistema; "expressivo" se reefre à necessidade de manter a integração das várias partes do sistema entre si, tanto quanto com o seu sistema normativo. Os papéis dos grupos podem então ser classificados como devotados primordialmente ao serviço de uma ou outra necessidade funcional. Paralelamente, os mesmos conceitos são úteis na classificação do papel das elites quanto à iniciativa e ao contrôle, as quais dirigem as atividades desenvolvidas nos vários grupos pelos seus seguidores.

Finalmente, os participantes em geral e os lideres em particular, têm pretensões psicológicas instrumentais ou expressivas. Certamente esta é, em parte, uma distinção situacional. O fatu cle um membro tornar-se um lider expressivo ou instrumental depende, em parte, das predisposições psicológicas dos outros membros do seu grupo, e uma pessoa pode adquirir algumas das caracteristicas dêsse tipo de liderança (por ex.., maior nivel de atividade, habilidade para enfrentar a hostilidade), uma vez assumindo a posição a êle correspondente, quando entra em contato com seguidores ou com lideres do tipo complementar. Ainda mais, poder-se-ia prever, com base em um teste psicológico, o provável tipo de liderança que determinada pessoa irá assumir. A liderança instrumental parece atrair as pessoas mais agressivas, mais capazes de enfrentar hostilidade e mais desejosas de ser respeitadas, enquanto que a liderança expressiva atrai as pessoas mais acomodativas, menos capazes de suportar hostilidade, e mais desejosas de ser amadas.

Analisando êstes vários niveis de aplicação dos conceitos gêmens "expressivo" e "instrumental", a teoria da dupla liderança sugere - embora exista aqui uma grande falta de dados - que os grupos orientados para o trabalho (ou tarefa) serão mais eficazes em têrmos de consecução de objetivo e satisfação dos membros. quando estâo presentes tanto o lider instrumental como o expres sivo. Isto sugere ainda que, embora êstes dois tipos de liderança pudessem ser encontrados numa só pessoa (o "grande homem"), não é comum acontecer. Finalmente, quando duas exercem os dois 
tipos de liderança referidos, é necessário o apoio mútuo para a efetiva liderança do grupo. Esta teoria contrasta com a orientação predominante na literatura de Psicologia, Administração e Ciência Política, que esperam a liderança efetiva vinda de um só homem.

Nem tôdas estas afirmações são inteiramente baseadas em evidências empíricas, nem o que existe está imune a interpretações conflitantes. Não obstante, essas afirmativas podem ser empregadas para desenvolver proposições outras, que, certamente, requerem validação elas próprias.

A teoria da dupla liderança, ràpidamente exposta aqui, desenvolveu-se especialmente em estudos experimentais de grupos orientados para tarefa e grupos "naturais" na comunidade. Mas, pouco esfôrço tem havido até aqui para aplicar tal teoria a grupos em organizações complexas. No estudo de comitês a teoria tem sido utilizada como se os participantes constituíssem um outro grupo "natural", que não deve fazer caso do comportamento organizacional externo dos indivíduos, nem do fato de que êles não se relacionam como pessoas, mas como representantes de departamentos, serviços ou outras organizações.

Antes de tentar reunir as linhas de análise de dupla liderança e das organizações complexas, torna-se necessário mais um comentário preparatório. Para tratar da articulação de grupos e organizações, tenho como ponto central o conceito de liderança. Liderança é a habilidade, baseada em qualidades pessoais do indivíduo, para conseguir dos seguidores aceitação voluntária em uma ampla gama de assuntos. Liderança distingue-se do conceito de poder, no que a primeira inclui influência, isto é, modificação de preferências, enquanto que o último implica apenas em que as preferências do individuo são contidas .

Em relação a pequenos grupos, a liderança guia as atividades pelas quais as suas necessidades expressivas e instrumentais são satisfeitas. A questão aqui é: que contribuições deve esperar o pequeno grupo dos lideres que lhe são proporcionados, em seus esforços para responder essas necessidades? Em relação à organização, o veiculo mais importante para a orientação dos seus membros no quie toca a motivação e orientação normativas, é a habilidade em proporcionar liderança aos pequenos grupos aos quais êles pertencem. (Esta espécie de ponte não existe com freqüência; mas, raramente ela existe sem liderança). Se os participantes aceitam êsse lider provido pela organização (isto é, um que esteja engajado nas metas da organização, sua estrutura, seu pessoal), pode ser obtida a sua participação não calculista. Se êles rejeitam a liderança organizacional, a eficácia da instituição fica restrita à manutenção da lei e da ordem e à elaboração dos tipos mais 
rotineiros de produção, isto é, às taretas que requeiram relativamente pouco envolvimento emocional da grande maioria dos membros. O estudo da liderança - as suas conseqüências provindo de vários niveis organizacionais, sua orientação em relação à organização e o seu âmbito de influência - propicia assim uma orientação proveitosa para o estudo de pequenos grupos em organizações complexas.

\section{DUPLA LIDERANÇA EM ORGANIZAÇÕES}

As organizações diferem de outras coletividades no ponto em que dentro delas o poder é, comparativamente, distribuido de maneira mais deliberada e institucionalizada. O poder é focalizado nas posições de elite formalmente reconhecidas, nas quais estâo concentrados os simbolos de status, o direito de conceder ou recusar recompensas econômicas, e o contrôle dos meios de violência. Em grupos de trabalho experimentais a liderança apóia-se apenas no comportamento dos membros e reciprocidades, de maneira que surgem poucas discrepâncias entre as posições de liderança e de poder, mas tais discrepâncias são comuns em organizações complexas. Um individuo pode reter apenas o poder relativo do cargo, caso em que poderia ser chamado "funcionário"; pode exercer apenas uma influência pessoal genérica, sendo então chamado de "lider informal": ou então, êle pode ser enquadrado nas duas categorias, quando é chamado "lider formal". Se o individuo não dirige nada, será então um subordinado (gráfico 1). Estes conceitos não são novos, mas, definidos desta forma, passam a integrar
uma concepção sistemática.

Quando a proposição da dupla liderança é aplicada a pequenos grupos em organizações complexas, os problemas críticos não sãı apenas se os dois tipos de liderança estão presentes e se apóiam mùtuamente, mas inclui também a questão de "como e até que ponto a liderança é apoiada pelo poder organizacional". Um grupo dentro de uma organização, cuja dupla liderança seja exercida por lideres informais - pessoas sem cargo na hierarquia - será
muito diferente de um outro onde os lideres sejam formais pessoas com cargo na hierarquia - ou ainda de um terceiro, onde um dos tipos de liderança é exercido por um líder formal e o outro
não.

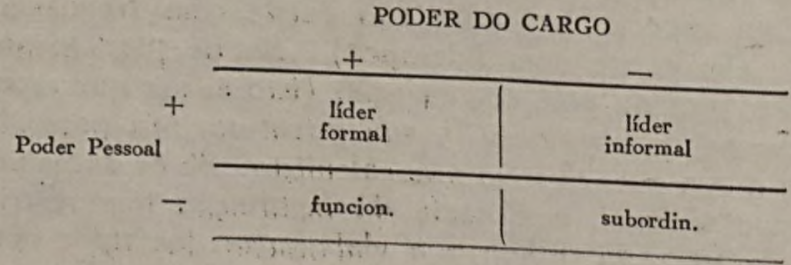


Localização organizacional da liderança expressiva e instrumental afeta: a) o grau de contrôle da organização sôbre o grupo; b) o grau de colaboração entre os dois tipos de lideres; c) as relações de poder entre os dois tipos de líderes. Cada um dêstes pontos merece uma rápida explanação.

A propiciação de liderança provinda das posições existentes na organização é da maior importância como fonte de contrôle organizacional sôbre os grupos de participantes. A posse de um cargo na hierarquia não assegura automàticamente a fidelidade do seu ocupante às metas da organização, suas regras ou seus lideres dos niveis superiores, nem a sua falta implica necessàriamente em alienação do líder; mas, se tudo o mais fôr igual, os lideres informais tendem a ser menos apegados à organização do que os formais. Portanto, de um modo geral, uma organização que apresente os dois tipos de liderança (isto é, seus representantes são aceitos como líderes pelos membros dos pequenos grupos), terá maior soma de contrôle sôbre os seus membros do que uma outra em que os dois tipos de atividade sejam controlados por lideres informais.

A eficácia de uma organização que apresenta apenas um dos dois tipos de liderança para os seus membros não segue um padrão definido, de vez que o efeito desta configuração é contaminado pela natureza das relações entre os dois lideres. Esta. segunda variável, colaboração entre a liderança instrumental e a expressiva, é ela própria afetada pelas posições organizacionais dos dois líaeres. Todos os outros aspectos sendo iguais, a colaboração é mais provável quando ambos os líderes ocupam cargos na hierarquia ou quando nenhum dos dois o ocupa, do que o seria se apenas um tivesse posição hierárquitica. Quando ambos os lideres detêm cargos na linha hierárquica, a colaboração pode apoiar-se em vários mecanismos organizacionais, como seja, recompensas (por ex., promoções mais rápidas para líderes que se dão bem com outros) e normas e pontos institucionalizados (por ex., o que vem a seguir no comando) para solucionar conflitos, e por experiência de treinamento compartilhada, perspectivas organizacionais e ideologia. Certamente, quando não é êste o caso, como se dá quando um dos dois lideres foi recentemente de fora, ou está mais propenso a agradar seus subordinados do que ser recompensado pela organização, as probabilidades são de que a colaboração diminua; ainda mais, em média essa diferença de experiência, perspectivas e expectativas deveria ser menos comum entre dois lideres formais do que entre um lider formal e outro informal.

E mais comum a semelhança entre os lideres informais do que entre êstes e aquêles formais, porque o seu rendimento, prestígio, interêsses, etc., guardam relação com a classe, e os líderes 
informais de um mesmo pequeno grupo tendem a ser do mesmo nivel, Pertencendo a uma classe similar, êles podem enfrentar um grupo organizacional fechado, para o qual não possam ser recrutados (por ex. enfermeiras face aos médicos ou, convocados face aos militares profissionais); sua organização pode tardar nas promoções (por ex., professôres jovens nas universidades européias); êles podem partilhar de terem sido deixados para trás uma organização onde a promoção rápida é a regra, ou de terem recusado com base ideológica ou psicológica uma posição de liderança organizacional.

Finalmente, as relações entre os lideres expressivos e instrumentais são grandemente afetadas pelos seus recursos relativos. Os últimos dependem de suas posições na hierarquia que, por sua vez, são influenciados pelas metas e pela estrutura de aceitação da organização. Em reuniões de grupos de 4 ou 5 pessoas, com duração de 45 minutos, numa situação altamente institucionalizada, as únicas fontes são pessoais; nenhum membro comanda, no sentido organizacional, não sendo portanto afetadas as relações entre os dois lideres. Mas, quando o contexto é o de uma organização complexa, o problema do seu poder relativo é mais importante: qual dos lideres está em nivel superior (ou em outra situação em relação ao poder organizacional) - o expressivo ou o instrumental? Supondo que todos os outros aspectos sejam iguais, a concessão de maior poder "organizacional" a um tipo de lider afeta as metas às quais o pequeno estiver dedicado primordialmente. Em outras palavras, se o lider instrumental é o superior, o grupo será mais orientado no sentido do trabalho (tarefa), enquanto que se lider expressivo é superior, o grupo terá uma característica sócio-normativa. É licito esperar que as metas da organização determinem se um grupo funcionando dentro dela é predominantemente expressivo ou instrumental.

Mas, as metas da organização precisam ganhar apo:o; elas não se traduzem automàticamente em ação adequada. Recrutando pessoal com alta potencialidade de liderança, a organização poderá trazer os grupos a uma atitude de concordância com suas metas, através de um treinamento em liderança, bem como destinando um nivel superior para um certo tipo de lider. Entretanto, se a hierarquia de liderança contraria as metas de organização, é muito mais provável que apareça um grupo predominantemente expressivo na organização (os trabalhadores "fazendo cêra", fazendo camaradagem com o chefe, jogando cartas no trabalho, etc.), como também se pode dar o contrário.

A observação crítica ligada ao pequeno grupo e às linhas organizacionais de análise é que, para maximizar sua eficácia, a organização não deve apenas adquirir o contrôle do grupo através 
dos seus líderes, mas, também, precisa distribuir o poder de modo que se estabeleça a superioridade do tipo de liderança desejado sôbre o outro. Os mecanismos para êste propósito incluem a concessão de um nível superior a um dos lideres, símbolos de maior prestígio, maior apoio do superior imediato, etc. Alguém poderia pensar que uma organização complexa deveria apoiar sempre o líder instrumental, de vez que ela é bàsicamente um órgão orientado no sentido instrumental. Mas, a resposta difere de um tipo de organização para outro, e deve ser procurada segundo uma perspectiva de comparação interinstitucional (distinta da intercultural).

Contrariando uma suposição amplamente aceita e perpetuada em muitos livros-texto sôbre administração geral e industrial, as organizações diferem notadamente no grau em que o funcionamento eficaz requer que elas consigam o contrôle e a lealdade dos pequenos grupos que dentro delas funcionam. Em algumas organizações - prisões, por ex. - êsse contrôle é muito difícil de alcançar, raramente é tentado, e não é essencial para um funcionamento eficaz. Em outras organizações - movimentos politicos ou religiosos - o contrôle é francamente possivel, freqüentemente procurado, e um pré-requisito para o funcionamento eficaz. Os efeitos da organização sôbre as relações entre lideres expressivos e instrumentais deveriam ser examinados segundo esta variáve!.

Para nossos objetivos presentes, é bastante classificar as organizações de acôrdo com suas metas e as correspondentes necessidades de um engajamento de baixo, médio ou alto grau de seus membros. As organizações cuja atribuição é segregar membros márginais da sociedade - prisões, instituições correcionais e hospitais para doentes mentais - requerem participação relativamente baixa por parte dos seus membros (servidores e internados) para niveis satisfatórios de funcionamento. As suas chances de conseguir o contrôle dos pequenos internos provendo-lhes uma liderança, são pequenas em qualquer dos casos, de vez que os participantes estão geralmente contra a organização, e tendem a rejeitar qualquer liderança que ela tente apresentar-lhes, instrumental ou expressiva. Os servidores procuram satisfazer suas tarefas apoiando-se amplamente no poder, não na liderança. A liderança nos pequenos grupos tende a ser informal, e o lider expressivo é provàvelmente o superior, de vez que êsses grupos estão orientados primordialmente para problemas sociais e normativos. Êsses grupos formam a base da vida social em organizações do tipo de prisões e se constituem na origem de tensões, além de reforçar normas especiais dos internados. Os lideres instrumentais, tais como os traficantes de artigos proibidos, tendem a um status e poder inferiores ao dos "bons sujeitos", os lideres expressivos dos internados. Quando os grupos informais de internados se organizam em tôrno de esforços para 
fugir, e os líderes instrumentais têm a seu cargo os aspectos técnicos da fuga, o seu status e poder se tornam superiores mas, ainda assim, êles tendem a ser subordinados aos lideres expressivos. (Isto sugere que o preparo de uma fuga é mais normativo do que operações calculadas racionalmente).

No extremo oposto do continuo da participação estão as organizações cuja meta real é a socialização ou ressocialização dos membros da sociedade: escolas, centros de reabilitação, hospitais de doenças mentais e organizações religiosas. As organizações religiosas pertencen a esta categoria, na medida em que uma de suas metas principais é fortalecer essa que tende a desvanecer-se na vida secular, necessitando portanto ser reforçada. Nesse sentido elas se constituem em órgãos de ressocialização.

A socialização efetiva requer um alto nivel de participação da parte dos seus membros, de vez que, sem tal participação, sem identificação dos estudantes, pais, paroquianos, com a liderança organizacional e suas metas, a organização não poderá atuar fundamente em suas personalidades. Por isso, tais organizações devem, ou prover a liderança nos pequenos grupos, ou ganhar o apoio dos lideres. Se os esforços não tiverem sucesso, e a lealdade estiver restrita ao grupo, não se estendendo à organização, é pràticamente inevitável o fracasso. As condições para atingir a liderança dêsses grupos são muito melhores aqui do que no tipo de organização segregacional, de vez que a participação é voluntária e os meios de contrôle são muito mais simbólicos que coercivos. As atitudes dos membros tendem a ser positivas, e os seus grupos são mais receptivos à liderança organizacional. A organização, por sua vez, investe muito mais no treinamento para liderança e no contrôle simbólico dos participantes, e, na medida em que domina outros tipos de poder, reluta muito mais em empregá-los.

O lider subordinado de pequenos grupos nas organizações organização é afetar objetivo primordial da propósito éão é afetar os seus membros; os seus agentes para êsse propósito são os lideres expressivos - professôres, terapeutas, ministros - que, ou agem diretamente sôbre os participantes, ou pelo menos atuam indiretamente, influenciando o pequeno grupo no cual os participantes estejam envolvidos (por ex., classes ou grupos em tratamento). Cada organização (e cada pequeno grupo) tem, é claro, necessidades instrumentais. Os edificios precisam ser cuidados, as verbas precisam ser distribuidas, e assim por diante. Ainda mais, estas considerações dizem respeito à aquisição e distribuição de recursos cuja natureza difere daquela relativa às metas de organização. Diversamente da meta de lucros, os objetivos da socialização são tais que, simplesmente combinando melhor os recursos, ou dando maior status às posições instrumèn- 
tais e às lideranças instrumentais, reduz a eficácia da organização. ( $\mathrm{O}$ que foi dito acima, acentue-se, não diz respeito à cúpula das organizações em pauta, mas àqueles que ocupam o nivel imediatamente superior ao dos membros, ou seja, professôres, funcionários de hospitais psiquiátricos, párocos, etc.).

As organizações cuja meta é produzir bens ou serviços, ou ainda trocá-los, - como seja, fábricas, lojas, bancos - requerem maior engajamento de seus participantes, inclusive os dos niveis inferiores, do que as organizações segregacionais; mas, podem funcionar com eficácia apresentando níveis consideràvelmente inferiores de participação em relação à socialização. Via de regra, as organizações de produção operam com maior eficácia se sua liderança é aceita pelos pequenos grupos internos. Se a liderança organizacional fôr rejeitada, entretanto, essas entidades podem operar, ainda assim, com maior eficácia do que usualmente se diz. Os participantes podem "negociar" com a organização um "bom trabalho diário" por um "bom salário diário", sem comprometimento com sua meta (lucro), com muitas de suas regras, ou com sua administração. Isto bem se caracteriza quando o trabalho é rotineiro, requerendo pouca iniciativa ou responsabilidade. Essas últimas qualidades são difíceis de medir ou supervisionar, e requerem participação interna e recompensas outras que não apenas remunerativas. É mais fácil para uma organização construir uma pirâmide sem a integração dos seus membros do que conduzir uma pesquisa relativa a uma alunissagem. As organizações de produção, portanto, tendem a apoiar-se em um misto de poder "oficial" (especialmente remunerativo) e liderança. Que proporções são mais eficazes, depende do tipo de trabalho realizado, de acôrdo com as dimensões sugeridas acima.

Não falando do quanto de liderança uma organização de produção requer (e quanto ela realmente comanda), a sua máxima eficácia é claramente conseguida, fazendo-se a liderança instrumental superior à expressiva. Neste sentido, as organizações de produção contrastam frontalmente com aquelas de socialização. A combinação ótima de meios é mais relevante para o sucesso de uma organização de produção do que o são o moral e a vida social de seus trabalhadores. A produção requer a concessão de prioridade aos cálculos que envolvem divisão do trabalho, designação de pessoal, e logo, de fato, o interêsse das organizações nas atividades "expressivas" dos grupos de participantes é largamente instrumental. A atenção a essas atividades, inclusive o provimento de liderança organizacional para elas, iustifica-se pelo fato de que ela encarece o contrôle das atividades instrumentais. A necessidade de líderes expressivos é, assim, secundária. Se devessem prevalecer as considerações expressivas, os aspectos relativos à 
produção teriam que ser significativamente preteridos em favor de boas relações sociais entre os trabalhadores e seu chefe. Embora os chefes, não com pouca freqüencia dêem precedência aos aspectos expressivos, está claro que não é êste o intento da organização de produção, bem como não é o que a satisfação efetiva de suas metas exige.

Assim, cada tipo de organização tem uma necessidade diferente para o contrôle dos seus membros, isto segundo suas metas e o grau de integração que elas requeiram. Isto sugere uma relação ótima entre o líder instrumental e o expressivo para cada tipo de organização. As instituições segregacionais não exigem muita integração dos membros colocados nos niveis inferiores para operar com eficácia, e, de qualquer maneira, raramente afeta as relações entre o lider instrumental e o expressivo, os quais tendem a ser informais. As organizações socializantes necessitam prutunda integração dos membros dos níveis inferiores; a mudança dêsses participantes é o seu maior "produto". Isto requer subordinação dos aspectos instrumentais aos expressivos, o que, por sua vez, requer subordinação do lider instrumental ao expressivo. As organizações de produção requerem um grau médio de integração. O seu manejo dos membros dos niveis inferiores é subordinado a outros aspectos mais amplos da combinação de meios, dos quais o trabalho dos participantes é apenas um, de vez que o seu produto não é um estado de espírito dos membros, mas, bens ou serviços. O moral dos participantes (no mais amplo sentido do têrmo) é apenas um aspecto entre muitos, e o líder expressivo responsável por esta cateyoria está subordinado ao lider instrumental, que é encarregado da combinação mais ampla dos meios e mais "cal. culista" em suas relações com os trabalhadores. Desta forma, existe uma relação teórica entre o tipo de organização em causa e as relações de poder entre os dois tipos de lider.

\section{ALGUMAS APLICAÇÕES}

As proposições que adiantei aqui derivam de duas linhas de análise. Como acontece em tais casos, as derivações precisam vencer o teste da pesquisa empírica antes que sejam consideradas válidas. Sendo êsse o caso, elas terão implicações significativas para várias áreas da sociologia aplicada, áreas essas não relacionadas entre si, elas sugeririam revisões na sociologia da reabilitação, terapia, relações de trabalho e educação.

Grande parte da literatura nesses campos acentua as relações interpessoais, estilos de liderança, e atmosfera de grupo, como se os contextos estruturais nos quais são introduzidas fôssem imate- 
riais. Um supervisor "sensivel" ou "democrático" pode alcançar a liderança dos grupos de participantes, envolvendo assim a eficacia da organização. Mas, a análise precedente sugere que os fatôres estruturais e culturais limitam de maneira estrita 0 grau $\mathrm{cm}$ que um "agente" da organização, qualquer que seja o seu estilo, pode conseguir a liderança de um grupo de participantes, tanto quanto o tipo de liderança que êle pode exercer.

Se é válida a análise precedente, os esforços para captar a liderança expressiva dos grupos de internos em organiazções segregacionais designando uns poucos profissionais (assistentes sociais, psicólogos clinicos, psiquiatras) deve falhar, a menos que a estrutura básica da organização (medidas de segurança, restrições de privilégios, atitudes de guardas ou atendentes, etc.) seja modificada. Os grupos de internos nas organizações tendem a rejeitar os valôres da entidade, suas metas (êles acham que o seu confinamento é injusto), e seu pessoal (êles acham que os guardas são cruéis e arbitrários). Embora os líderes e grupos anti-organização tendam a prevalecer, e o pessoal profissional possa encontrar em tais ambientes internos isolados que não foram assimilados e aculturados pela comunidade, e que sejam propensos ao seu tratamento, os seus esforços serão em grande parte baldados, em virtude das fôrças contrárias da comunidade.

O contexto muda quando, em lugar de enviar uns poucos profissionais de reabilitação às organizações segregacionais, seu número e poder na organização é aumentado até um ponto em que êles podem modificar algumas de suas caracteristicas básicas. Mas, nós estaremos então lidando com um tipo diferente de organização, que é, ou se está tornando, do tipo socializante. Em comunidades segregacionais, os esforços isolados de reabilitação, os quais requeiram a influenciação das orientações e atividades expressivas dos internos tendem a falhar. Um sistema mais eficaz seria concentrar o pessoal disponivel em número suficientemente jrande para afetar a estrutura básica de algumas poucas organizações segregacionais, e designá-los para aquelas mais passiveis de mudar (como resultado de resultado de interêsse favorável por ex., ou enfraquecimento recente da estrutura coerciva), em lugar de distribuílos por um grande número de organizações, supondo que êles irão converter outras pessoas ao seu ponto-de-vista.

A análise precedente implica em que nas organizações de produção os supervisores treinados em "Relações Humanas" provàvelmente serão menos eficazes! A tradição de Relações Humanas procura fazer do supervisor um "grande homem", o que alguns podem ser e outros se podem tornar, mas cuja maioria decididamente não é, nem é capaz de se tornar grande homem. Espera-se 
de um supervisor o desempenho de dois papéis simultâneos, que seja um lider instrumental e expressivo ao mesmo tempo. Sob pressão da direção, dêle se espera a fixação de cargas de trabalho especificas, a supervisão da produção, a manutenção da maquinaria, o encorajamento da adesão a normas, etc. Êle poderia realizar tudo isto, se os trabalhadores considerarem o pagamento adequado e as condições de traballio satisfatórias, se não forem contrảrios ao sistema de produção, e se êle entende o processo de trabalho. Suponhamos que êle ingresse no treinamento de Relações Humanas; êle assiste seminários, debates, encontros com representantes do Departamento de Relações no Trabalho, e assim por diante. Ele é instado a se tornar também o lider expressivo dos trabalhadores, a ser não apenas respeitado, mas também admirado; com o fim de familiarizar-se com os problemas pessoais dos empregados, deverá participar de sua vida social, ser um "pai" e um "amigo".

Em um grau bem limitado um lider instrumental pode exercer liderança expressiva sem comandar os raros talentos de um "grande homem". Um supervisor pode tomar uma cerveja com seus homens ou ir ao boliche com êles sem perder sua autoridade. Mas, cedo ou tarde, a relação entre os seus compromissos expressivos e instrumentais gerará problemas. Quando a direção aumentar suas exigências, o supervisor tem que decidir se irá procurar contornar as novas demandas, mantendo assim sua popularidade com os trabalhadores, ou impor-lhes-á condições, o que provocará a alienação dos empregados e fará deteriorar-se a liderança expressiva que êle tenha conseguido. Tentar as duas coisas simultâneamente conduz a um nivel alto de tensão em relação ao supervisor. Êste tipo de tensão é antes aumentado do que reduzido com o. treinamento em Relações Públicas.

Uma outra consideração importante é a de que o supervisor, ao retomar do curso de Relações Públicas, provàvelmente irá encontrar a posição de liderança expressiva preenchida, e o ocupante sairá ganhando em qualquer conflito relacionado com o cargo. Essa pessoa pode ser um dirigente sindical ou mesmo um trabalhador com certa dose de influência; de qualquer modo, êle tem poucas, se é que tem alguma, caracteristica instrumental com que possa atuar sôbre os trabalhadores, sendo então possivel atuar como líder expressivo, apenas. Tais pessoas são, via de regra, selecionadas pelos trabalhadores; êsses lideres tendem a ser espontâneos e não impostos por quem quer que seja. Mas, o supervisor não é escolhido pelos trabalhadores e, em comparação com o lider expressivo informal, está mais distante em têrmos de salário e nivel. Uma vez que êle deve, pelo menos ocasionalmente, transmitir pressões da direção ao atuar em sua característica instrumental, o supervisor será provàvelmente derrotado na competição 
pela liderança expressiva. E não apenas falha em assegurar a posição de liderança expressiva; êle também arrisca uma possível coalizão com o ocupante do cargo. Embora as metas da organização de produção pudessem ser beneficiadas por essa coalizão, as Relações Públicas na realidade tornam isso impossível ou improvável, ensinando os supervisores a pugnar pela posição de líder expressivo.

A análise que fizemos é também relevante para a administração dos hospitais de terapia mental. Uma controvérsia neste campo focaliza o seguinte problema: deve o tratamento ficar em sua maior parte nas mãos dos psiquiatras, ou podem outros profissionais participar amplamente? Este problema é bastante complexo e tem muitas ramificaçeõs, mas um ponto está estreitamente relacionado com o assunto que aqui ventilamos. O tratamento psiquiátrico, com outros processos de socialização ou ressocialização, cnvolve um elemento de apoio que proporcione segurança emocional a insistência no encorajar o crescimento, a experimentação e a aprendizagem. Na familia primária, como existia na classe média do século XIX na Alemanha e na França, a mãe (ou a governanta) era provàvelmente a primeira fonte de apoio; o pai significava o crescimento ou desenvolvimento. Não queremos dizer que uma só pessoa não possa preencher os dois papéis. Numa atuação psiquiátrica de sucesso, o terapeuta preenche as duas posições, variando a quantidade de apoio relacionado com a pressão no sentido da melhora de sessão para sessão, e em particular, após várias etapas do tratamento. Mas uma divisão de trabalho entre o psiquiatra e um outro agente de ressocialização - uma enfermeira especializada, um assistente social, um psicólogo clínico - proporcionaria maior número de horas disponiveis para cada paciente, reduziria os custos por hora, e apressaria a melhora do paciente, de vez que o psiquiatra teria mais tempo para especializar-se no trabalho de pressão para o crescimento ou desenvolvimento.

A teoria aqui lançada, entretanto, não deve ser vista apenas como defendendo a participação de outros profissionais no processo de tratamento. A co-participação seria eficaz apenas se o psiquiatra (como lider instrumental) colaborasse com outros profissionais (lideres expressivos). Uma das melhores maneiras de assegurar tal coalizão é conceder uma nítida vantagem em status a um dos dois tipos de lideres, e, desde que nenhum dos participantes do grupo de tratamento possui tanto prestigio ou poder como o psiquiatra, êle é òbviamente a pessoa adequada para coordenar os esforços da terapêtutica. Acresce que o psiquiatra não pode nunca agir na qualidade apenas de lider instrumental, de vez que a êle competem a orientação e articulação dos aspectos expressivos do tratamento. 
Nos hospitais de doenças mentais dois ou mais membros do corpo de servidores, pelo menos, participam ativamente do processo de tratamento. Isto necessàriamente não reduz a eficácia do tratamento, como poderia sugerir a teoria da dupla liderança de Bales-Parsons, porque a liderança expressiva e a instrumentāl podem estar distribuidas entre mais de duas pessoas, como em uma familia ampliada. Tal divisão é atingida, quando vários prolissionais trabalham simultâneamente com o mesmo paciente. Seria desnecessário dizer da necessidade de harmonizar os esforços do tratamento, e assim institucionalizar a coordenação psiquiátrica, necessidade esta que aumenta com o crescimento do número de profissionais participantes.

Outras aplicações da análise que apresentamos podem ser mencionadas apenas de passagem. A maior parte das unidades de infantaria do Exército possui dois líderes providos institucionalmente, como seja, o oficial e o NCO, cuja divisão de trabalho parece seguir a linha "instrumental-expressiva". Os exércitos diferem grandemente, entretanto, no que toca ao tipo de liderança à qual é dado maior destaque, devido as razões ainda por explorar. Tôdas as organizações religiosas prevêem a liderança expressiva, mas diferem no grau de importância concedido aos lideres instrumentais (como seja no que se refere ao problema de deixar êste papel ao laicato). Finalmente, por razões que estão muito longe de ser claras, muitas escolas secundárias americanas não proporcionam liderança expressiva formal satisfatória. Alguns professôres atuam como lideres expressivos em certas escolas, mas, freqüentemente êles são empregados que possuem algum conhecimento especializado ou são responsáveis pela disciplina, de sorte que, pouco tentam e menos ainda conseguem no sentido de assegurar a liderança expressiva dos grupos de estudantes. Na realidade. o sistema de rodizio de aulas, que redistribui os estudantes de hora a hora, solapa a importância desta unidade organizacional, e por deficiência aumenta a importância do grupo não organizacional e seus lideres expressivos informais. Isto pode muito bem concorrer para a influência limitada dos professôres da escola secundária e sôbre as orientações normativas mais profundas dos seus estudantes. Qualquer organização que necessite uma integração positiva de seus participantes deve prover a liderança dos vários grupos, tanto a instrumental com a expressiva, ou ganhar a colaboração dos lideres informais, se quer realmente ser eficaz; mas, nem tôdas elas assim procedem.

Atrás dêstes e muitos outros problemas estudados permanece um aspecto analítico: o papel da dupla liderança no sentido de unir organizações e grupos de participantes. A liderança de grupos 
em organizações é um mecanismo fundamental, pelo qual grupos e organizações são articulados, que em parte reflete e em parte afeta o grau em que êsses grupos e organizações e suas considerações expressivas e instrumentais trabalham lado a lado ou com objetivos cruzados.

Publicado o original na American Sociological Review vol. $30 \mathrm{n}^{\circ} 5$ - out. 1965. 